\title{
Evaluation of maxillary anterior teeth and their relation to the golden proportion in malaysian population
}

\author{
Maan Ibrahim Al-Marzok ${ }^{1^{*}}$, Kais Raad Abdul Majeed ${ }^{2}$ and Ibrahim Khalil Ibrahim ${ }^{3}$
}

\begin{abstract}
Background: The maxillary anterior teeth are important in achieving pleasing dental aesthetics. Various methods are used to measure the size and form of them, including the golden proportion between their perceived widths, and the width-to-height ratio, referred to as the golden standard. The purpose of this study was conducted to evaluate whether consistent relationships exist between tooth width and height of the clinical crown dimensions; and to investigate the occurrence of the golden proportion of the maxillary anterior teeth.

Methods: Dental casts of the maxillary arches were made in this cross-sectional study from MAHSA University College students who met the inclusion criteria. The 49 participants represented the Malaysian population main ethnics. The dimensions of the anterior teeth and the perceived width of anterior teeth viewed from front were measured using a digital caliper.

Results: Comparison of the perceived width ratio of lateral to central incisor and canine to lateral incisor with the golden proportion of 0.618 revealed there were a significant statistical difference $(p<0.05)$. The statistical difference was significant for the width-to-height ratio of central incisors to the golden standard of $80 \%$. There was no significant difference in the comparison among ethnic groups for the golden proportion and the golden standard.

Conclusions: The golden proportion was not found to exist between the perceived widths of maxillary anterior teeth. No golden standard were detected for the width-to-height proportions of maxillary incisors. Specific population characteristics and perception of beauty must be considered. However, ethnicity has no association with the proportions of maxillary anterior teeth.
\end{abstract}

Keywords: Golden proportion, Malaysian ethnics, Aesthetics, Anterior teeth

\section{Background}

Dental esthetics is a primary consideration for patients. New dental materials and techniques were introduced maximizing the likelihood of an attractive outcome. The size and form of the maxillary anterior teeth are important not only to dental esthetics, but also to facial esthetics [1].

A system of esthetic predictions is described by Levin. The application of this system is facilitated by the use of a dental grid for the anterior esthetic segment [2], its use may help simplify the diagnosis of facial and dental

\footnotetext{
*Correspondence: maanalmarzok@gmail.com

'Department of Restorative Dentistry, MAHSA University College, Level 6,

Block E, Pusat Bandar Damansara, 50490, Kuala Lumpur, Malaysia

Full list of author information is available at the end of the article
}

disharmonies and treatment using this system will help restore optimal facial esthetics [3].

Dental and facial aesthetics are optimized if proportion between widths of maxillary anterior teeth is repeated when the patient is viewed from the front [4]. This proportion is called golden proportion and is approximately 0.618. In this manner the visible width of lateral incisor is $62 \%(0.618)$ of central incisor and the visible width of canine is $62 \%(0.618)$ of lateral incisor [5]. This golden proportion has been proposed in many articles and textbooks as an esthetic guideline for restoring and replacing maxillary anterior teeth [6,7].

One of the most important guidelines is golden standard value. According to this standard, the ideal width-toheight proportion of maxillary central incisor should be

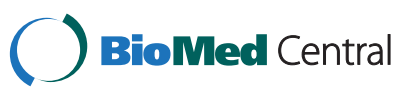


approximately $80 \%$ width compared with height [8]. A higher width/height ratio means a squarer tooth, and a lower ratio indicates a longer appearance [9].

The objective of the present study was to investigate the occurrence of the golden proportion between the perceived widths of the maxillary anterior teeth. A second objective was to evaluate whether consistent relationships exist between tooth width and height of the clinical crown dimensions. The null hypotheses were that there is no difference between the proportions of maxillary anterior teeth of Malaysian population and the golden proportion or the golden standard values. The study also aimed to compare these proportions among the 3 majority ethnic groups in Malaysia: Malay, Chinese and Indian.

\section{Methods}

A cross-sectional study was conducted over a period of 4 months for students of MAHSA University College in Pusat Bandar Damansara Campus.

The participants are selected according to the following criteria:

1. Complete maxillary and mandibular anterior teeth.

2. No periodontal disease.

3. No spacing and crowding in anterior maxillary teeth.

4. No history of orthodontic treatments.

5. No intruded, extruded or rotated teeth in the anterior region.

Using these criteria, 49 students were selected for evaluation represented the Malaysian population main ethnics: (22 Chinese, 14 Indians and 13 Malay). Their mean age was 18-23 years. Participants were asked to identify their ethnicity by selecting an answer using prefixed ethnicity categories (e.g. Malay, Chinese, Indian, Indigenous people, Mixed and Others). Then participants were also asked to identify their father's and mother's ethnicity using the same pre-fixed categories.

Ethical approval obtained from the Ethics Committee of the Faculty of Dentistry, MAHSA University College. All volunteers participated in the research signed informed consent prior to their participation which included the nature of the project and declared the confidentiality of all information.

Irreversible hydrocolloid impressions of the maxillary arches were made in stock trays and poured with Type IV dental stone. Making an alginate impression for the maxillary arch of a volunteer is shown in (Figure 1).

The dimensions of the anterior teeth and the perceived width of anterior teeth viewed from front were measured using a digital caliper read to the nearest $0.01 \mathrm{~mm}$. Evaluations regarding the occurrence of the golden proportion were conducted by drawing of grids that obtained by

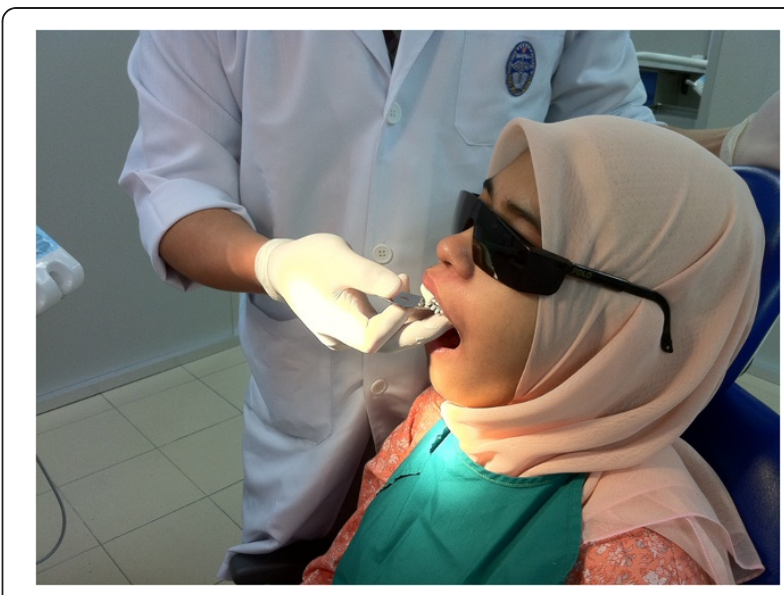

Figure 1 Making an alginate impression for maxillary arch of a volunteer.

placing the casts on a flat surface and drawing vertical lines representing the perceived mesiodistal widths of the teeth. The golden proportion grid is shown in (Figure 2).

Measurements were done for the spaces in the grids using the digital caliper as shown in (Figure 3). All measurements were performed by the three researchers working independently and the average of these measurements was taken; if the readings differed by more than $0.2 \mathrm{~mm}$, the procedure was repeated.

The 3 sets of measurements of each researcher were compared to check the intra-examiner repeatability. Intraclass correlation coefficient was $0.998,0.996$ and 0.988. Inter-examiner repeatability checked among the researchers and the correlation coefficient was 0.991 . These results showed that the measurements could be repeated with high accuracy.

A one-sample $t$ test was used to compare the widthto-height ratios of all tooth groups with the proportion

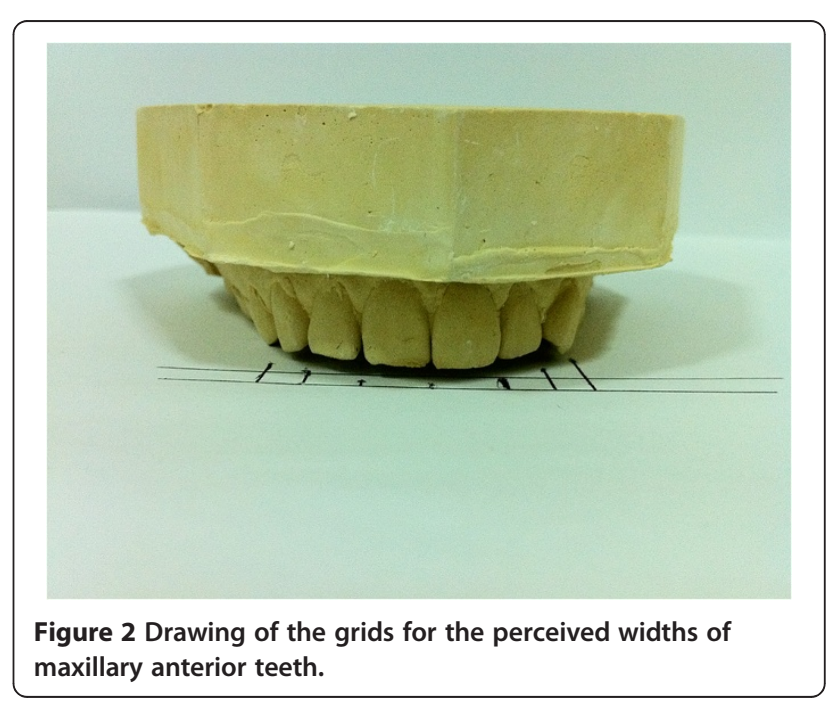




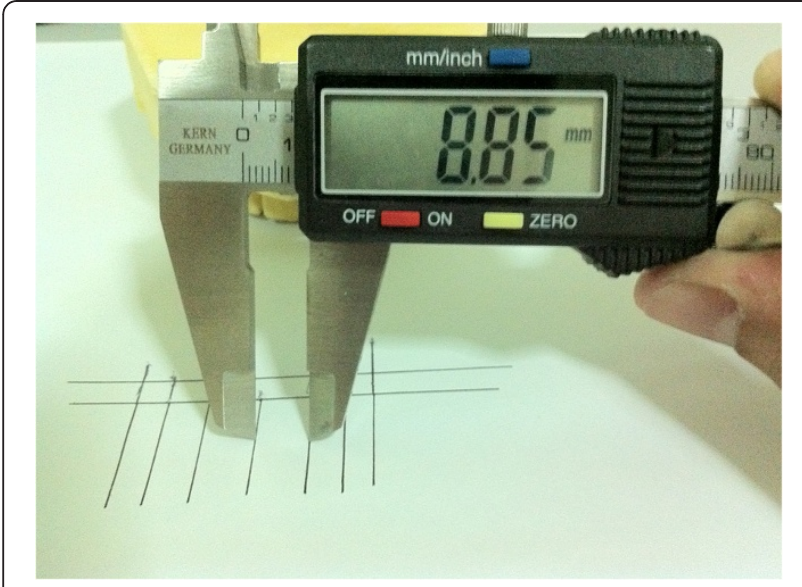

Figure 3 Taking measurements for the spaces in the golden proportion grid.

of $80 \%$ and to assess the incidence of the golden proportion of 0.618. One-way analysis of variance (ANOVA) was used to analyse the comparison among ethnics in the golden proportion and golden standards.

Statistical analyses were carried out using Statistical Package for Social Sciences (SPSS 16.0) with the Level of Significance $\alpha=0.05$ and Degree of confidence $\mathrm{d}=0.95$.

Post hoc power analysis was made using PS power and sample size program as suggested by Dupont and Plummer (1998) [10].

\section{Results}

The occurrence of golden proportion within the range of 0.55 to 0.64 (as measured by Mahshid et al., 2004) was found in $20.4 \%$ of the perceived lateral-to-central incisor ratios and in $20.4 \%$ of the perceived canine-to-lateral incisor ratio. The existence of golden proportion of the perceived lateral-to-central incisor ratio among ethnicities were as follows: $13.6 \%$ of Chinese, $35.7 \%$ of Indians and
Table 1 ANOVA table for lateral/central incisor ratio in each ethnic group

\begin{tabular}{lccccc}
\hline Ethnicity & $\mathbf{N}$ & Mean & SD & F- Statistic (df) & P value \\
\hline CHINESE & 22 & 0.738 & 0.080 & $1.251(2)$ & 0.291 (Non-Significant) \\
INDIAN & 14 & 0.710 & 0.083 & & \\
MALAY & 13 & 0.744 & 0.104 & & \\
\hline
\end{tabular}

$15.4 \%$ of Malay. The existence of golden proportion of the perceived canine-to-lateral incisor ratio among ethnicities were as follows: $13.6 \%$ of Chinese, $21.4 \%$ of Indians and $30.8 \%$ of Malay.

Ratios for maxillary lateral to central incisors and canine to lateral incisor based on the golden proportion are shown in (Figure 4). Narrower central incisors and wider canines compared to the lateral incisors were found for all ethnic groups rather than the golden proportion.

One-way ANOVA was used to analyze the comparison between ethnics of the lateral to central incisor ratio is demonstrated in Table 1; and of the canine to lateral incisor ratio is demonstrated in Table 2. The ANOVA Tables showed there were no significant difference in the comparison among the ethnic groups for the golden proportion.

One-sample $t$-test statistics revealed there were significant differences $(\mathrm{P}<0.05)$ emerged when the mean ratios between perceived widths of maxillary anterior teeth compared with the ideal golden proportion of $0.618(\mathrm{P}=0.026$ for lateral to central incisor ratio; $\mathrm{P}=0.017$ for canine to lateral incisor ratio). This indicates the golden proportion did not exist.

The occurrence of golden standard for the width-toheight ratio of maxillary central incisor within the range of $75 \%$ to $80 \%$ (as suggested by Peixoto et al., 2012) was found in $20.4 \%$ of the population. The existence of golden standard among ethnicities were as follows: $22.7 \%$ of Chinese, $21.4 \%$ of Indians and $15.4 \%$ of Malay.

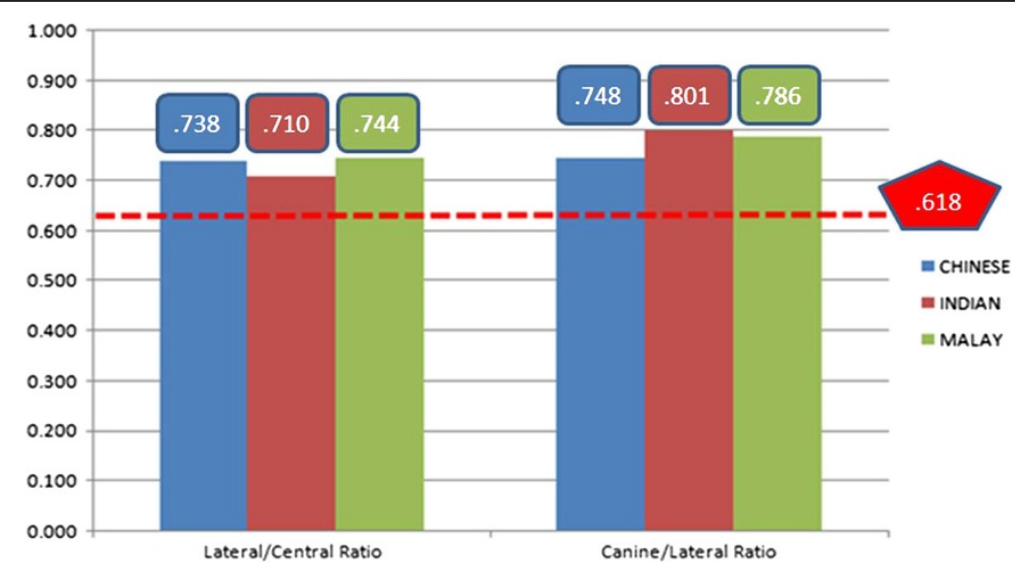

Figure 4 Mean values of the ratio of perceived widths of lateral to central incisor and canine to lateral incisor by ethnicity. The dotted line, the golden proportion of 0.62 . 
Table 2 ANOVA table for canine/lateral incisor ratio in each ethnic group

\begin{tabular}{lccccc}
\hline Ethnicity & $\mathbf{N}$ & Mean & SD & F- Statistic (df) & P value \\
\hline CHINESE & 22 & 0.748 & 0.092 & $1.949(2)$ & 0.148 (Non-Significant) \\
INDIAN & 14 & 0.801 & 0.139 & & \\
MALAY & 13 & 0.786 & 0.133 & & \\
\hline
\end{tabular}

The means for the widths and heights of the maxillary central incisors are shown in (Figure 5). More square central incisors were found (more than $85 \%$ for all ethnics) for all ethnic groups rather than the golden standard.

Table 3 represents the one-way ANOVA that was used to analyze the comparison between ethnics of the widthto-height ratio of maxillary incisors. The ANOVA Table showed there was no significant difference among the ethnic groups for the golden standard.

One-sample $t$-test statistics was used for the assessment of width-to-height ratio of central incisors. There were significant differences $(\mathrm{P}=0.022<0.05)$ emerged when the mean ratios compared with the proportion of $80 \%$ to assess the incidence of golden standards. This showed that no golden standard was observed.

\section{Discussion}

The results of this study displayed no specific effect of ethnicity on golden proportion and golden standard among the three major Malaysian ethnic groups. Ethnicity has a close association with genetics. It is of no doubt that the ethnicity will affect the tooth proportions greatly between population and ethnics. However, this is an exception if the population has intermarried and not considered "pure" ethnic. Similar traits may be observed in different populations originate from same continent [11].

Many dental and facial characteristics differ following the geographical location and historical background. Therefore, information regarding tooth norms in a group of population is useful to dentists when restoring teeth [12].
Table 3 ANOVA table for width/height ratio of central incisor in each ethnic group

\begin{tabular}{lccccc}
\hline Ethnicity & $\mathbf{N}$ & Mean (\%) & SD (\%) & F- Statistic (df) & P value \\
\hline CHINESE & 22 & 85.60 & 5.28 & $0.471(2)$ & 0.625 \\
INDIAN & 14 & 87.15 & 7.96 & & (Non-Significant) \\
MALAY & 13 & 86.05 & 6.49 & & \\
\hline
\end{tabular}

The general Malaysian data can be used in the current study to compare with other populations as the golden proportion and golden standard was not found in all ethnic groups.

Determination of a mathematical or geometrical relation between anterior teeth is important to achieve an esthetic result. It would be helpful if statistically reliable results existed to support existing theories [13]. However, the golden proportion idea can no longer be considered since many articles found that golden proportion didn't exist.

Rosenstiel and others found that golden proportion was preferred only when viewing very tall teeth and less desirable for normal height or shorter teeth [14]. Ward in 2001 recommended using other ratios, such as 0.70 rather than 0.618 to provide more pleasing appearance [15].

The current study found poor correlation between teeth dimensions and the golden proportion which is similar to 'the findings of (Preston in 1993, Gillen et al. in 1994, Mahshid et al. in 2004, Hasanresioglu et al. in 2005, Fayyad et al. in 2006, Murthi and Ramani in 2008 and Petricevic et al. in 2008) [1,13,16-20].

The results for Malaysian population were comparable to the results reported in similar studies of other populations, including Turkish [1], Iranians [5,18], Jordanians [13], Americans [16], Indians [19] and Caucasians [20].

Peixoto et al. reported that the ideal $\mathrm{W} / \mathrm{H}$ ratio for the central incisor should lie between 75 and 80\%. However, the ratio which allows an aesthetically acceptable appearance is in the 65 to $85 \%$ range [9].

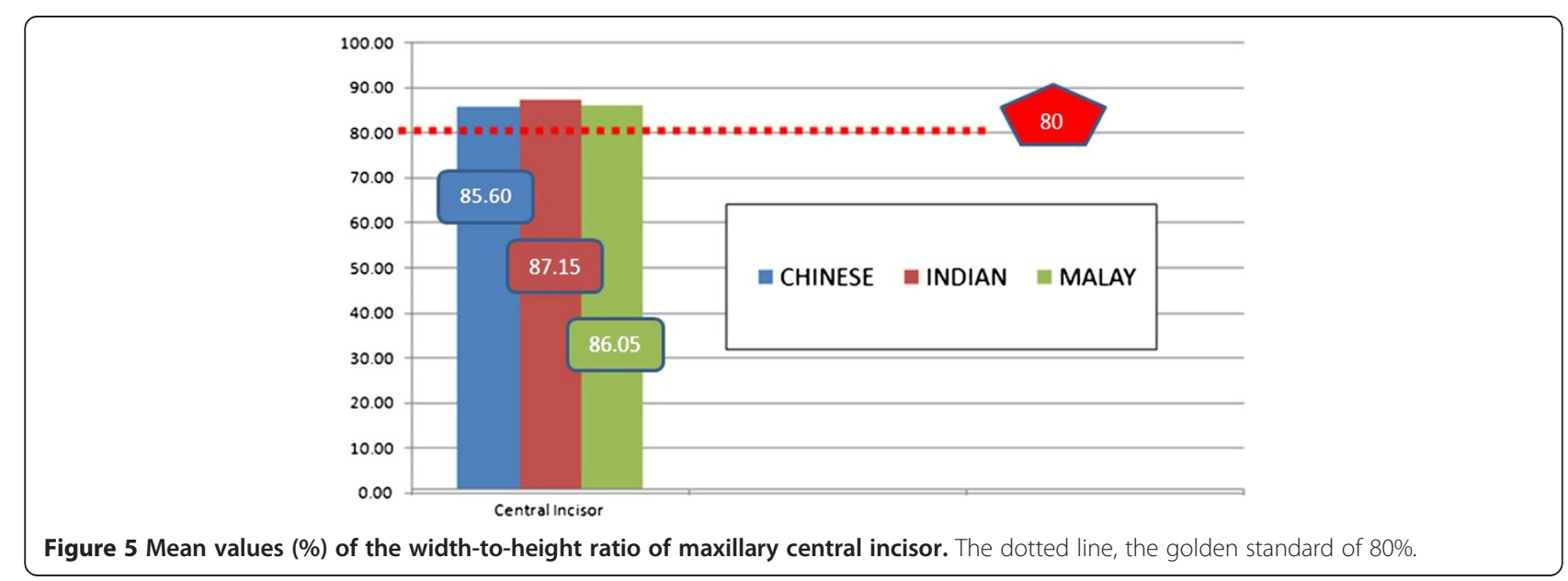


According to Hasanresioglu et al., the highest $\mathrm{W} / \mathrm{H}$ ratio is found in squarer teeth due to shorter height and/or greater width than those of other population which came in agreement with the result of this study [1].

The results of this study showed $\mathrm{W} / \mathrm{H}$ ratio higher than other studies (Hasanresioglu et al. in 2005, Wolfart et al. in 2006, Parnia et al. in 2010) although these studies estimated that there is no golden standard in the nature $[1,5,8]$. Recent study conducted in Korea showed similar results for the non-celebrities group [21]. These results might be attributed to differences in racial characteristics.

Power analysis was used to find how much power for this cross-sectional study if we had a specified number of volunteers. The power analysis of $65 \%$. This indicates that there is a $65 \%$ chance of rejecting the null hypothesis when it's false while $80 \%$ is generally considered to be good power.

With small sample size, the sample mean tends to be noticeably larger than when the null hypothesis is rejected with the larger sample size. Literatures reveal small difference in means between current study and studies with larger sample sizes.

In the present study, limitation such as minor inaccuracies common to the making of dental cast might have affected the measurements. Time constraints and the exclusion criteria restricted the number of volunteers who could be recruited into the study. Additional research on a greater sample size selected more systematically is needed before extrapolating the results to the Malaysian population.

\section{Conclusions}

Within the limitations of this study:

1. The golden proportion was not found to exist between the perceived widths of maxillary anterior teeth.

2. No golden standard were detected for the width-toheight proportions of maxillary incisors.

3. Ethnicity has no association with the proportions of maxillary anterior teeth.

4. Specific population characteristics and perception of beauty must be considered.

Competing interests

The authors declare that they have no competing interests.

\section{Authors' contributions}

MAL-M took part in making the study conception and design, supervision of the research group, analysis and interpretation of data, involved in drafting the manuscript. KRA-M participated in the design of the study and involved in drafting the manuscript. IKI involved in drafting the manuscript. Authors read and approved the final manuscript.

\section{Acknowledgements}

We would like to express our gratitude to Ms. Agnetha Tan Tjin, Mr. Ong Wui Liam and Mr. Lee Yen Yao; the dental students at MAHSA University College for their efforts in getting volunteers' consent, data collection and taking photographs. Our thanks to everyone who has helped as a volunteer especially to Ms. Aimi Khadijiah Binti Abdul Razak for approval of publishing her picture. A written consent was obtained for publication of study. This study was supported by Faculty of Dentistry, MAHSA University College which approved the study proposal and offered all the instruments and materials.

\section{Author details}

${ }^{1}$ Department of Restorative Dentistry, MAHSA University College, Level 6,

Block E, Pusat Bandar Damansara, 50490, Kuala Lumpur, Malaysia.

${ }^{2}$ Department of Conservative Dentistry, International Islamic University

Malaysia, Kuantan, Malaysia. ${ }^{3}$ Department of Prosthetic Dentistry, Ajman

University of Science and Technology, Ajman, United Arab Emirates.

Received: 24 July 2012 Accepted: 22 January 2013

Published: 24 January 2013

\section{References}

1. Hasanresioglu U, Berksun S, Arus K, Aslan I: An analysis of maxillary anterior teeth: facial and dental proportion. J Prosthet Dent 2005, 94:530-538.

2. Levin El: Dental esthetics and the golden proportion. J Prosthet Dent 1978, 40(3):244-252.

3. Singh R, Datta K: The golden proportion. God's Building block for the world. J Indian Prosthodontic Soc 2008, 8(1):6-9.

4. Lombardi RE: The principles of visual perception and clinical application to denture esthetics. J Prosthet Dent 1973, 29:358-382.

5. Parnia F, Hafezegoran A, Mahboub F, Moslehifard E, Koodaryan R, Moteyagheni R, Saber FS: Proportions of maxillary anterior teeth relative to each other and to the golden standard in Tabriz dental faculty students. JODDD 2010, 4(3):83-86.

6. Levin El: The updated application of the golden proportion to dental aesthetics. Aesthetic Dentistry today 2011, 5(3):22-27.

7. Rosenstiel SF, Land MF, Fujimoto J: Contemporary fixed prosthodontics. 3rd edition. St. Louis: CV Mosby; 2001:598-599.

8. Wolfart S, Quass AC, Freitag S, Kroop P, Greber W, Kern M: Subjective and objective perception of upper incisors. J Oral Rehabil 2006, 33:489-495.

9. Peixoto LM, Louro RL, Gomes AA, de Nascimento APC: Photographic analysis of esthetic dental proportions. Rev Gaucha Odontol 2012, 60(1):13-17.

10. Dupont WD, Plummer WD: Power and sample size calculations for studies involving linear regression. Controlled Clin Trials 1998, 19:589-601.

11. Abd.Rahman ANA and Othman Sl: Comparison of tooth size discrepancy of three main ethnics in Malaysia with Bolton's ratio. Sains Malaysiana 2012, 41(2):271-275

12. Yaacob H, Nambiar $P$, Naidu MDK: Racial characteristics of human teeth with special emphasis on the Mongoloid dentition. Malaysian J Pathol 1996, 18(1):1-7.

13. Fayyad MA, Jamani KD, Aqrabawi J: Geometric and mathematical proportions and their relations to maxillary anterior teeth. JCDP 2006, 7(5):62-70.

14. Rosenstiel SF, Ward DH, Rashid RG: Dentists' preferences of anterior teeth proportion. A web-based study. J Prosthodont 2000, 9(3):123-136.

15. Ward DH: Proportional smile design using the resurring esthetic dental (RED) proportion. Dent Clin North Am 2001, 45:143-155.

16. Priston JD: The golden proportion revisited. J Esthet Dent 1993, 5:247-251.

17. Gillen RJ, Schwartz RS, Hilton TJ: An analysis of selected normative tooth proportion. Int J Prosthodont 1994, 7:410-417.

18. Mahshid M, Khoshvagti A, Varshosaz M, Vallaei N: Evalution of golden proportion in individuals with an esthetic smile. J Esthet Restor Dent 2004, 16:185-192.

19. Murthi BVS, Ramani N: Evaluation of natural smile: golden proportion, RED or golden percentage. J Conserv Dent 2008, 11(1):16-21.

20. Petricevic N, Stipetic J, Antonic R, Borcic J, Strujic M, Kovacic I, Celebic A: Relations between anterior permanent teeth, dental arches and hard palate. Coll Antropol 2008, 32(4):1099-1104.

21. Ku JE, Yang HS, Yun KD: A morphometric analysis of maxillary central incisor on the basis of facial appearance in Korea. J Adv Prosthodont 2012, 4:13-17.

doi:10.1186/1472-6831-13-9

Cite this article as: Al-Marzok et al:: Evaluation of maxillary anterior teeth and their relation to the golden proportion in malaysian population. BMC Oral Health 2013 13:9. 